\title{
Toxoplasmose do sistema nervoso central em paciente sem evidência de imunossupressão: relato de caso
}

\author{
Toxoplasmosis of the central nervous system in patient \\ without immunossupression: case report
}

\author{
Luciana Almeida Silva', Roseli Stone Vieira', Luciano Neder Serafini², \\ Carlos Gilberto Carlotti Junior ${ }^{3}$ e José Fernando de Castro Figueiredo ${ }^{1}$
}

Resumo O quadro clínico da toxoplasmose adquirida em pacientes imunocompetentes habitualmente não inclui manifestações neurológicas focais, o que é freqüente em pacientes imunodeprimidos, como aqueles com síndrome da imunodeficiência adquirida. Este trabalho tem como objetivo relatar o caso de uma paciente adulta que apresentou abscessos cerebrais por Toxoplasma gondii, sem evidência de qualquer fator causador de imunossupressão.

Palavras-chaves: Toxoplasmose. Imunocompetentes. Abscesso cerebral. Neurotoxoplasmose.

\begin{abstract}
The clinical manifestations of acquired toxoplasmosis in the immunocompetent patient rarely include localized neurological signs, which are frequent in the immunosuppressed patient (Aids). The objective of this paper is to report the case of a woman with Toxoplasma gondii brain abscess, without an identified cause of immunosuppression.
\end{abstract}

Key-words: Toxoplasmosis. immunocompetence. Brain abscess. Brain toxoplasmosis.

A evolução clínica da toxoplasmose adquirida em pacientes imunocompetentes é habitualmente benigna e a infecção é, na maioria das vezes, assintomática. Os sinais e sintomas mais comuns são a linfadenite e a febre, acompanhadas por astenia e mialgia ${ }^{2}$. Em casos raros pode ocorrer acometimento neurológico secundário a esta infecção e, geralmente, se expressa por encefalite ou meningoengefalite, com sintomas inespecíficos e sem manifestações neurológicas focais. O início pode ser marcado por cefaléia, sonolência e mudança de comportamento, com duração variável de dias ou semanas, seguido por coma, convulsões, síndromes piramidal ou cerebelar, paralisias oculares e transtornos psíquicos ${ }^{13467}$. A encefalite geralmente é difusa e raramente observam-se lesões focais levando a manifestações localizatórias, como hemiparesias ou hemiplegias ${ }^{36}$. Dessa forma, tais manifestações em pacientes imunocompetentes dificilmente levam à suspeita diagnóstica de toxoplasmose do sistema nervoso central, o que retarda o diagnóstico e o início do tratamento e, como conseqüência, piora o prognóstico. Este relato tem como finalidade ressaltar a toxoplasmose como causa possível de acometimento focal do sistema nervoso central em pacientes imunocompetentes.

\section{RELATO DO CASO}

Paciente do sexo feminino, com 46 anos de idade, branca, solteira, costureira, natural e procedente de Cajuru, SP, foi atendida em 26/11/1999 apresentando desmaios e diminuição da acuidade visual há 8 dias. Os familiares relatavam também perda progressiva da capacidade de desempenhar suas tarefas habituais como dona de casa. A paciente já era acompanhada no Serviço de Neurologia do HCFMRP-USP, desde
1981, por apresentar crises convulsivas parciais complexas, atribuídas a calcificações intracranianas secundárias a neurocisticercose. Ao exame clínico, no momento da admissão, apresentava dificuldade de interagir com o examinador, monoparesia do membro superior esquerdo, exaltação de reflexos osteo-tendinosos e edema de papila do nervo óptico à direita.

1. Divisão de Moléstias Infecciosas e Tropicais do Departamento de Clínica Médica da FMRP/USP. 2. Setor de Neuropatologia do Departamento de Patologia da FMRP/USP. 3. Divisão de Neurocirurgia do Departamento de Cirurgia da FMRP da Universidade de São Paulo, Ribeirão Preto, SP.

Endereço para correspondência: Prof. José Fernando de Castro Figueiredo. Deptº de Clínica Médica/FMRP/USP, Av. Bandeirantes 3900, 14048-900 Ribeirão Preto, SP.

e-mail: jfcfigue@fmrp.usp.br.

Recebido para publicação em 26/3/2001. 
A tomografia computadorizada de crânio revelou lesão hipodensa com edema vasogênico em lobo occipital direito, com captação do contraste de forma heterogênea ao redor da lesão (Figura 1). A Ressonância Nuclear Magnética de crânio revelou imagem heterogênea em lobo occipital direito medindo $3,5 \times 2,9 \times 3 \mathrm{~cm}$, com edema perilesional, e áreas de alto sinal em T1 e T2. Havia lesão com as mesmas características, próxima à lesão anterior, em contato com a dura-máter (Figura 2). Foi submetida à exploração neurocirúrgica, tendo sido evidenciadas duas lesões nodulares, de aspecto pardo-amarelado, com áreas de necrose e cavitações no seu interior, a maior medindo $3,5 \times 2,5 \times 2 \mathrm{~cm}$ e a menor $1,0 \times 0,7 \times 0,5 \mathrm{~cm}$. O exame histopatológico do material ressecado durante 0 procedimento cirúrgico revelou processo inflamatório crônico circundando material necrótico, permeado por células linfomononucleares, a maioria das quais, macrófagos vacuolizados (células grânulogordurosas). Ocasionalmente observavam-se pseudocistos repletos de bradizoítos (Figura 3), melhor evidenciados à reação imuno-histoquímica direcionada a antígenos de superfície do Toxoplasma gondii (Figura 4). Outros exames complementares de interesse para o caso revelaram: IgG anti- $T$. gondii $=1 / 1.000$ e IgM negativo no soro; anti-HIV negativo; pesquisa do RNA do HIV no plasma (PCR) negativa; contagem de linfócitos $\mathrm{T} \mathrm{CD}_{4}{ }^{+}=683 / \mathrm{mm}^{3}$; teste de redução do NitroBlue Tetrazolium normal; teores de $\mathrm{lgG}=1458 \mathrm{mg} / \mathrm{dl}$, $\operatorname{lgM}=453 \mathrm{mg} / \mathrm{dl}$ e $\lg \mathrm{A}=326 \mathrm{mg} / \mathrm{dl}$ no soro; glicemia e teste de tolerância à glicose normais. Não foi realizada punção liquórica.

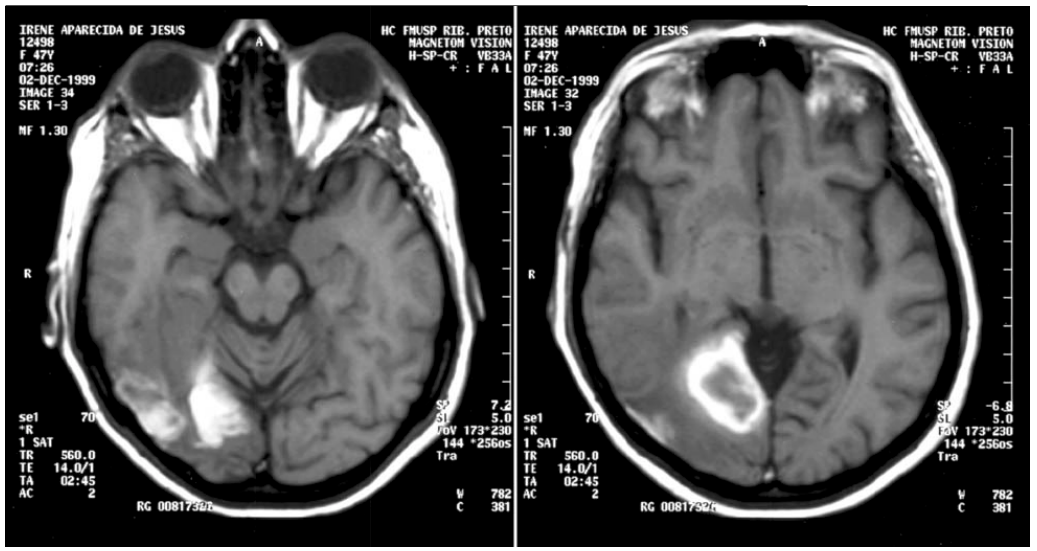

Figura 1 - (A e B). Tomografia computadorizada, com e sem contraste. Lesão hipodensa têmporo-occipital à direita circundada por edema vasogênico com intenso reforço anelar após administração de contraste. Há foco hemorrágico adjacente à lesão.

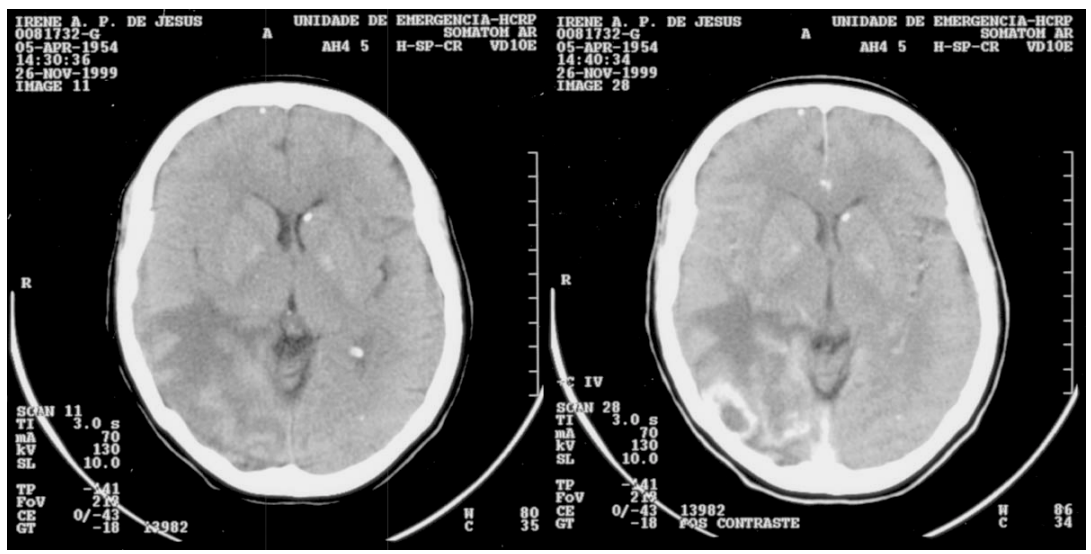

Figura 2 - (A e B). Ressonância nuclear magnética (T1) (TR 560/TR 14). Zona de reforço anelar cortical com foco hemorrágico justa-cisternal. 


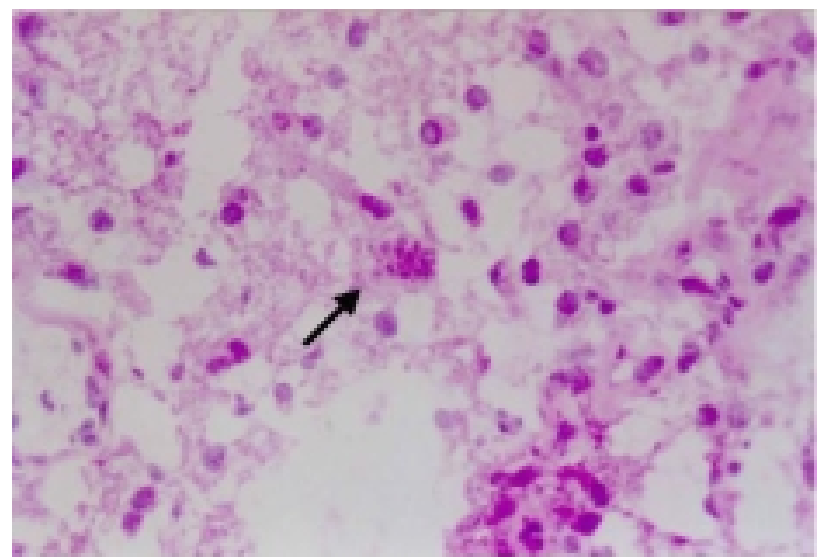

Figura 3 - Pseudocisto de Toxoplasma gondii (seta) com numerosos bradizoitos em seu interior (400XH\&E).

Após a confirmação diagnóstica, foi iniciado tratamento com sulfadiazina $(4 \mathrm{~g} / \mathrm{d})$ e pirimetamina $(50 \mathrm{mg} / \mathrm{d}$, com redução posterior para $25 \mathrm{mg} / \mathrm{d}$ após uma semana), associados ao ácido folínico durante

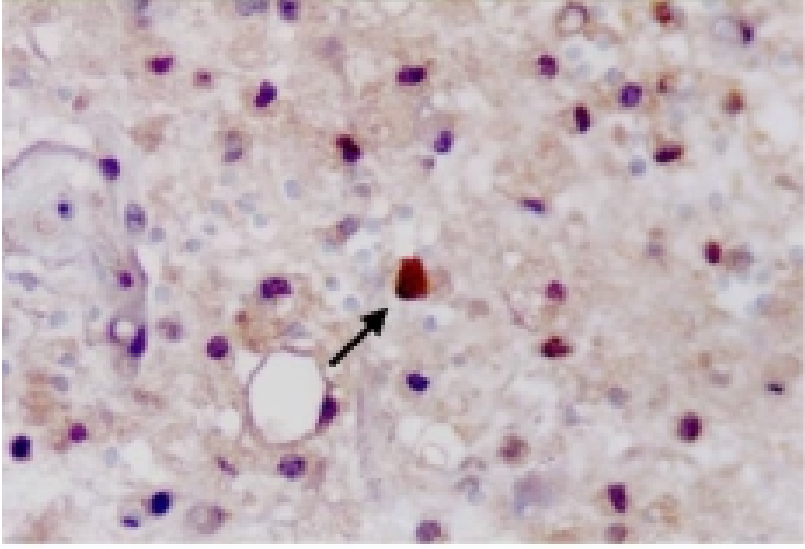

Figura 4 - Reação imunohistoquímica utilizando anticorpo antiToxoplasma gondii. Notar a maior imunorreatividade da reação aos bradizoitos (seta) (400X).

todo o tratamento. Houve melhora progressiva dos sinais e sintomas neurológicos iniciais e, seis meses após o diagnóstico, já sem tratamento, referia somente hipoestesia nos pés, sem outras queixas.

\section{DISCUSSÃO}

A descrição do caso evidenciou paciente com sinais neurológicos indicativos de lesão expansiva no sistema nervoso central e cujos exames de imagem revelaram lesões focais, com captação periférica do contraste e edema perilesional, imagens compativeis com as lesões causadas pelo Toxoplasma gondii em pacientes com síndrome da imunodeficiência adquirida. A conduta inicial foi a pesquisa do anti-HIV no soro, por método imunoenzimático, pela possibilidade diagnóstica de neurotoxoplasmose, causa mais freqüente das lesões observadas na paciente, no nosso meio. Diante do resultado negativo do teste, passou-se a considerar como mais provável o diagnóstico de doença neoplásica e a paciente foi submetida à abordagem cirúrgica da lesão, cuja avaliação anátomo-patológica revelou tratar-se de abscesso em organização por Toxoplasma gondii. Após a confirmação deste diagnóstico, em razão de sua apresentação clínica não usual, a paciente foi submetida a nova avaliação de seu estado imunitário, com resultados normais ou negativos, convalidando o diagnóstico de abscessos cerebrais por toxoplasmose em pacientes imunocompetentes, raramente descritos na literatura ${ }^{3} 6$.

Cabe atentar para o fato de que a paciente apresentava títulos sorológicos compatíveis com infecção pregressa pelo Toxoplasma gondii. Os casos relatados na literatura referem-se, na maioria das vezes, a abscessos cerebrais complicando a infecção aguda pelo protozoário, com presença de IgM anti-Toxoplasma no soro ${ }^{1467}$.

No presente caso não foi possível definir se ocorreu reativação de uma infecção antiga desencadeada por um fator imunodepressor não identificado, ou, infeção aguda com envolvimento do sistema nervoso central pelo Toxoplasma gondii, com IgM negativo no soro.

O envolvimento do sistema nervoso central pelo Toxoplasma gondii em indivíduos não imunossuprimidos é um evento relativamente incomum, podendo manifestar-se clínicamente como encefalopatia inespecífica, meningoencefalite difusa ou mesmo como lesões expansivas ${ }^{6}$, como no presente caso.

Após a exérese cirúrgica completa das lesões cerebrais e a instituição da terapêutica para toxoplasmose ${ }^{56}$, a recuperação clínica ocorreu de forma progressiva e completa, não sendo prescrito tratamento de manutenção a longo prazo. A paciente continua em seguimento ambulatorial, sem definição de qualquer fator de imunossupressão até o momento, um ano após o diagnóstico. 


\section{REFERÊNCIAS BIBLIOGRÁFICAS}

1. Desguerre I, Pedespan JM, Buissonnère R, Couvreur J, Ponsot G. Toxoplasmose cérébrale acquise chez un enfant non immunodéprimé. Archives Françaises Pediatrie 50:339-342, 1993.

2. Hakes TB, Armstrong D. Toxoplasmosis. Cancer 52:15351540, 1983.

3. Khan EA, Correa AG. Toxoplasmosis of the central nervous system in non-human immunodeficiency virus-infected children: case report and review of the literature. The Pediatric Infectious Diseases Journal 16:611-618, 1997.
4. Lescop J, Brinquini L, Schill H, Soulié D, Sarrazin JL, Cordoliani YS. Encéphalite toxoplasmique diffuse chez un sujet non immunodéprimé. Journal de Radiologie 76:21-24, 1995.

5. Luft BJ, Remington JS. AIDS commmentary Toxoplasmic encephalitis. The Journal of Infectious Diseases 157:1-6, 1988.

6. Townsend JJ, Wolinsky JS, Baringer JR, Johnson PC. Acquired Toxoplasmosis. Archives of Neurology 32:335-343, 1975.

7. Triki A, Couvreur J. Les manifestations neuro-méningées de la toxoplasmose acquise. La Tunisie Medicale 49:323-329, 1971. 